\title{
Epidemiological Implications of Host Biodiversity and Vector Biology: Key Insights from Simple Models
}

\author{
Andrew D. M. Dobson* and Stuart K. J. R. Auld \\ Biological and Environmental Sciences, University of Stirling, Stirling FK9 4LA, United Kingdom \\ Submitted April 17, 2015; Accepted November 19, 2015; Electronically published February 29, 2016 \\ Online enhancement: zip file. Dryad data: http://dx.doi.org/10.5061/dryad.t24pq.
}

\begin{abstract}
AвSTRACT: Models used to investigate the relationship between biodiversity change and vector-borne disease risk often do not explicitly include the vector; they instead rely on a frequency-dependent transmission function to represent vector dynamics. However, differences between classes of vector (e.g., ticks and insects) can cause discrepancies in epidemiological responses to environmental change. Using a pair of disease models (mosquito- and tick-borne), we simulated substitutive and additive biodiversity change (where noncompetent hosts replaced or were added to competent hosts, respectively), while considering different relationships between vector and host densities. We found important differences between classes of vector, in cluding an increased likelihood of amplified disease risk under additive biodiversity change in mosquito models, driven by higher vector biting rates. We also draw attention to more general phenomena, such as a negative relationship between initial infection prevalence in vectors and likelihood of dilution, and the potential for a rise in density of infected vectors to occur simultaneously with a decline in proportion of infected hosts. This has important implications; the density of infected vectors is the most valid metric for primarily zoonotic infections, while the proportion of infected hosts is more relevant for infections where humans are a primary host.
\end{abstract}

Keywords: vector-borne disease, tick-borne disease, biodiversity, dilution effect, disease risk.

\section{Introduction}

Vector-borne diseases (VBDs) account for significant proportions of global human mortality and morbidity (Hay et al. 2010; Bhatt et al. 2013; Campbell-Lendrum et al. 2015). Concerns have been growing that anthropogenic activities such as climate change, pollution, human migration, deforestation, and encroachment into previously undisturbed habitats are exacerbating VBD risk in certain parts of the world (Harvell et al. 2002; Semenza and Menne 2009; Kilpatrick and Randolph 2012; Wesolowski et al. 2012; Parham et al.

\footnotetext{
* Corresponding author; e-mail: andrew.dobson@stir.ac.uk.
}

Am. Nat. 2016. Vol. 187, pp. 000-000. (C) 2016 by The University of Chicago. 0003-0147/2016/18704-56218\$15.00. All rights reserved.

DOI: $10.1086 / 685445$
2015). The consequences of changes in the community of animals acting as hosts for infectious disease, including VBDs, have received particular attention in recent years (e.g., Keesing et al. 2006, 2010; Pongsiri et al. 2009; Johnson et al. 2013; Wood et al. 2014).

The transmission of any vector-borne pathogen involves at least two other species - a vector and a host - and often many more (Auld and Tinsley 2015). For example, Borrelia burgdorferi sensu lato, which causes Lyme disease, is vectored by several different species of tick and is maintained by systemic infections in an array of hosts from three classes of vertebrate (Spielman et al. 1985; Matuschka et al. 1992). Altered abundance of any of these biotic components may cause changes in vector infection prevalence for a given disease and, therefore, the risk of exposure for a given host, such as humans (Matuschka and Spielman 1986; Ostfeld and Keesing 2000). Links between biodiversity and individual disease risk are thus inevitable, though the consistency of the relationship is still debated (Randolph and Dobson 2012; Lafferty and Wood 2013; Ostfeld 2013; Ostfeld and Keesing 2013; Randolph and Dobson 2013; Wood and Lafferty 2013).

The dilution effect has become the label for the process whereby an increase in biodiversity reduces the prevalence of a given infection. It has been studied in a large variety of disease systems, both vector-borne and directly transmitted, and in hosts from plant and animal kingdoms (LoGiudice et al. 2003, 2008; Allan et al. 2009; Johnson et al. 2009; Haas et al. 2011; Young et al. 2013; Lacroix et al. 2014). When first described in the context of zoonotic VBDs, the key metric was the proportion of infected vectors (PIV; Ostfeld and Keesing 2000), but the dilution effect literature has since broadened to include a range of metrics, in part because PIV is not as important as the density of infected vectors when considering human risk (Keesing et al. 2006; Ogden and Tsao 2009). It is, however, important to distinguish between the prevalence of a particular infection and the prevalence of disease in general. It is widely accepted, for example, that the diversity of pathogenic organisms (and, 
therefore, the overall disease burden in a community) is spatially correlated with biodiversity (Guernier et al. 2004; Wood et al. 2014). By contrast, the dilution effect applies specifically to the reduction in the prevalence of a single, given infection under conditions of host community diversification and assumes that a diversifying community acquires at least one host that is poorer at transmitting the infection. Increased host biodiversity may be associated with dilution of one particular disease but may also lead to increased prevalence of other diseases (Ostfeld and Keesing 2012; Randolph and Dobson 2012).

Nevertheless, some general rules regarding biodiversityprevalence relationships for individual VBDs can be identified. Two fundamental factors are expected to influence epidemiological responses to host community change. The first factor is the transmission function, that is, the mathematical relationship relating transmission to host density. The two basic functions are frequency dependent (FD) and density dependent (DD; though there are important variants to consider; see Wonham et al. 2006). In FD transmission, the per capita force of infection is determined by the frequency of infected individuals; for VBDs, this effectively means that an individual host's chance of becoming infected is determined by the ratio of infected vectors to hosts. In DD transmission, the same individual's risk is simply a function of the absolute density of infected vectors. DD transmission is assumed to apply to directly transmit- ted diseases such as influenza or measles, whereas FD transmission best describes sexually transmitted infections such as HIV but is also typically applied to VBDs. Increased host diversity is held to dilute individual disease risk where transmission is FD (Rudolf and Antonovics 2005; Ostfeld and Keesing 2012; Mihaljevic et al. 2014), but when DD transmission is assumed, the outcome should depend on the nature of the host change (see below).

The second factor concerns the nature of the host community change. The simplest model of host community change is one where a community with a single species of competent host becomes a community with one competent host and one noncompetent host, or vice versa. There are many ways in which this may occur, and we focus on the two scenarios that could be considered the extremes of a continuum: substitutive change, where host diversity increases without any change in overall host density; and additive change, where the addition of a second host species brings about a commensurate increase in overall density. Intuitively, dilution should occur after a substitutive increase in diversity (fig. $1 A$ ). When a proportion of reservoir-competent hosts is replaced by noncompetent hosts, a similar proportion of vector bites is, in effect, wasted. This results in a lowered (diluted) prevalence of infection in the next generation of vectors (Matuschka and Spielman 1986). By contrast, if change is additive, the outcome is thought to depend on the transmission function: dilution with FD transmission and amplification with DD

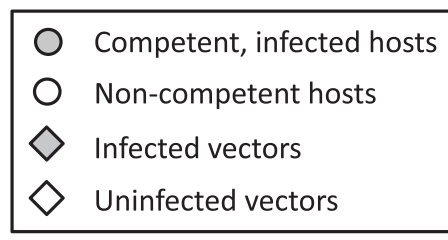

a

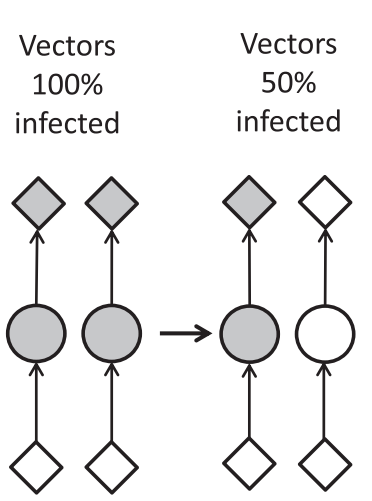

b

$\begin{array}{cc}\text { Vectors } & \text { Vectors 50- } \\ 100 \% & 100 \% \\ \text { infected } & \text { infected }\end{array}$

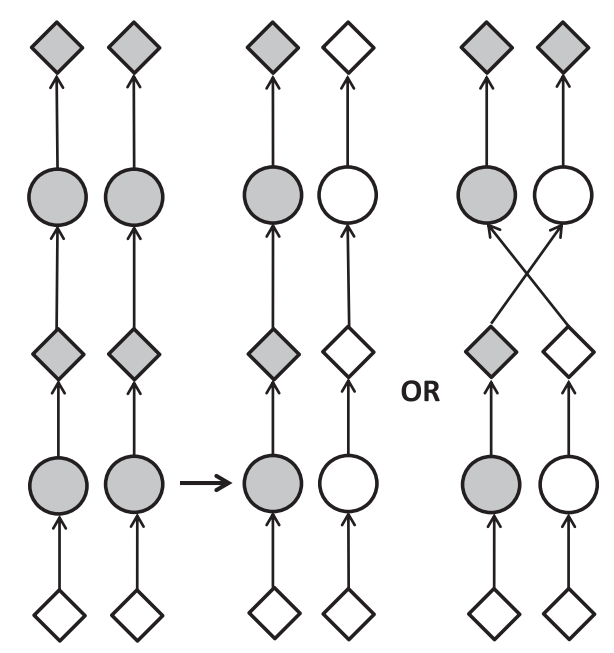

Figure 1: $a$, Dilution in a vector-borne disease. Substituting noncompetent hosts for competent ones reduces the prevalence of infection in vectors accordingly. $b$, A schematic that incorporates multiple vector feeding. The wasted bites on noncompetent hosts will, to an extent, be nullified by subsequent bites on competent, infected hosts. The actual vector infection prevalence will fall between $50 \%$ and $100 \%$. 
transmission (Rudolf and Antonovics 2005; Ostfeld and Keesing 2012; Mihaljevic et al. 2014).

One can also consider the numerical response of vectors to changes in host density. If host diversity is associated with host abundance, and if this subsequently determines vector population size, then any reduction of infection prevalence in vectors may be outweighed by increases in their absolute numbers (Dobson 2004; Ogden and Tsao 2009). There are four possible vector responses to an increase in host density: (i) no increase, (ii) a linear relationship between host and vector abundance, (iii) a less-than-linear relationship, and (iv) a more-than-linear relationship. The likelihood of a particular response will depend on the biology of the vector. For example, all motile life stages of ticks are parasitic; hence their populations are likely to be most strongly influenced by host abundance. For mosquitoes, the relationship between host and vector abundance appears to be more variable; survival of the nonbiting larvae (as opposed to adult feeding success) often determines the dynamics of mosquito populations (Rueda et al. 1990; Reiter 2001; Paaijmans et al. 2007), but there are also many examples from the literature of host abundance driving adult mosquito abundance (e.g., McLaughlin and Vidrine 1988; Brown and Sethi 2002; Minikawa et al. 2002). Furthermore, the mobility of winged insects means that their probability of feeding within a given time period will be less limited by host density than that of ticks, because tick feeding success depends mainly on opportunistic contact with passing hosts (Randolph 2004). These differences in life cycle and mobility mean that, typically, increases in host density are more likely to lead to an equivalent increase in vector density for ticks than for winged insects. For ticks in particular, this density increase could theoretically be more than linear-leading to an exponential increase in tick numbers - since each individual tick's chance of encountering a host increases with host density (Dobson and Randolph 2011). This should continue until high tick densities elicit host responses (e.g., grooming or immune reactions) that halt tick population growth (Randolph 1994; Kelly and Thompson 2000; Dobson et al. 2011). The nature of the numerical response influences the transmission function: an FD transmission function effectively approaches DD transmission if vectors respond more than linearly to an increase in host density, because the ratio of vectors to hosts (and, therefore, the bites per host) increases with host density (Ogden and Tsao 2009).

The numerical response is not, however, the only area in which vector biology can influence the epidemiological impact of changes in host community composition. Most biting insects take multiple, small blood meals, whereas most ticks (especially ixodids) will typically take just three, large meals during their lifetimes (Randolph 1998). This has important implications for disease transmission: in the context of dilution, wasted bites matter far more for tick-borne than insect-borne pathogens. For these reasons, models of infectious disease transmission may not be fully applicable to real-world VBDs if the vector is not explicitly modeled. Here, we demonstrate the role of vector biology in mediating the relationship between host biodiversity and disease prevalence using simple yet biologically realistic models. There is a rapidly growing empirical and theoretical literature on the dilution effect and related phenomena, and the interpretation of these studies will be aided by models that identify both the general and the idiosyncratic features of focal disease systems.

\section{The Models}

We present a pair of models of VBD transmission under conditions of vertebrate host community change: one for a generic mosquito-borne disease (MBD) and one for a generic tick-borne disease (TBD). These models are timestructured Leslie matrices that move in steps of 3 days for the mosquito model and 30 days for the tick model. Each model comprises a host component and a vector component that interact in order to calculate probabilities of mutual infection. For each model, we calculated two metrics: the change in density of infected vectors (DIV) and the change in proportion of competent hosts infected (PIH).

\section{Mosquito Model}

Both competent and noncompetent hosts have two life stages: immature, lasting 1 year, and adult (fig. 2; table 1). Adults reproduce once per year, and each has four offspring per reproductive event. Host life span is not fixed but instead follows an exponential distribution, with a mean life span of approximately 12.8 months. Hosts move between "susceptible," "infected," and "recovered" classes, and in initial simulations, recovered individuals cannot become reinfected (see "Transmission Success and Host Recovery"). The number of bites received by each host depends on the vector biting probability and the number of vectors per host. Infected hosts recover with probability $R$. The baseline adult vector-host ratio is set at $2.5: 1$; this corresponds to a daily per-host bite probability of $\sim 0.83$ (vectors are assumed to bite once per 3-day time step), in line with empirical observations of mosquito biting rates on humans (Mbogo et al. 2003). In the supplementary materials (available online), we also present data for model simulations where the initial ratios are $1.25: 1$ and $5: 1$.

The mosquito vectors have two discrete life stages: a juvenile stage, encompassing the transition from egg to larva to pupa, lasting 12 days, and an adult stage, lasting 30 days (fig. 3; table 2). Adults bite a host and produce 50 eggs every 3 days, irrespective of host density, and bites are spread 


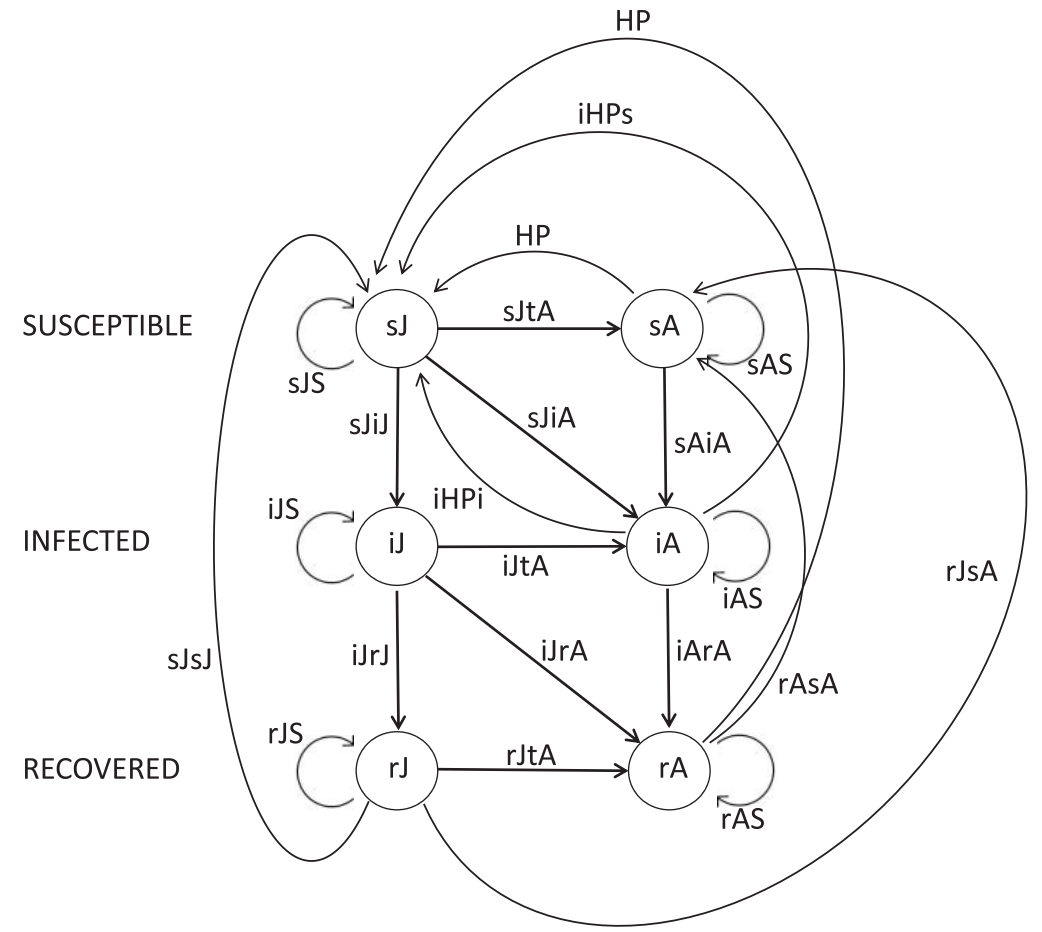

Figure 2: Flow diagram for competent host model, which is a stage-classified matrix model. In mosquito models, individuals move between stages every 3 days; in tick models, individuals move monthly. The stages (in circles) sJ, sA, iJ, iA, rJ, and rA correspond to susceptible juvenile, susceptible adult, infected juvenile, infected adult, recovered juvenile, and recovered adult, respectively. The noncompetent host model comprises only the two susceptible age classes. Definitions and values of the coefficients may be found in table 1 .

equally across available hosts. Bites on infective hosts infect the vector with probability determined by a variable probability of transmission success, and these vectors remain infected for life. We assume that male vectors do not bite, so matrix models explicitly follow only females (as a consequence, clutches effectively comprise 25 eggs). The following equations describe the calculation of numbers of newly infected hosts following an infective vector bite:

$$
\begin{aligned}
b & =\frac{\mathrm{iV}}{H}, \\
\mathrm{iH}_{t+1} & =\mathrm{sH}_{t} \times\left[1-(1-r)^{b}\right],
\end{aligned}
$$

where $b$ is the total number of infective bites received by each host per time step, iV is the number of infective vectors, $\mathrm{iH}, \mathrm{sH}$, and $H$ are the numbers of infected, susceptible, and all hosts, respectively, and $r$ is the probability of transmission success. The following equation describes the equivalent process of calculating the number of infective vectors that result from bites by susceptible vectors on infected hosts:

$$
\mathrm{iV}_{t+1}=V_{t} \times r \times \frac{\mathrm{iH}}{H}
$$

where $\mathrm{iV}$ and $V$ are the number of infected vectors and all vectors, respectively. Note that, in these models, vector-tohost and host-to-vector transmission success probabilities are equal (table 2).

\section{Tick Model}

Host biology is identical to that in the mosquito model. The maximal value of nymphal ticks per host (during the seasonal peak of tick activity) is 50 . This is the number of nymphs engorging per month. If it is assumed that the average nymph feeding event takes 3 days to complete, then this is equivalent to each host feeding a maximum of five nymphs at any given time, in line with empirical observations undertaken during peak tick activity periods (Duncan et al. 1978; Matuschka et al. 1991; Carpi et al. 2008). Data on larval and adult tick burdens are rare and unreliable (due to detectability and low numbers, respectively). So while we still model bites from larvae and adults, we calibrate the vector-host ratio by reference to nymphs only. In the supplementary materials, we also present data for model simulations where the initial ratios are 2.5:1 and 10:1.

The tick vectors have three discrete life stages: larva, nymph, and adult, each lasting 1 year (Belozerov and Nau- 
Table 1: Parameters for the host components of models

\begin{tabular}{|c|c|c|c|}
\hline \multirow[b]{2}{*}{ Parameter } & \multirow[b]{2}{*}{ Definition } & \multicolumn{2}{|c|}{ Value } \\
\hline & & Mosquito model & Tick model \\
\hline$R$ & Probability of recovery & $0-.045$ & $0-.45$ \\
\hline$f$ & Probability of reinfection & $0, .631$ & 0,1 \\
\hline$r$ & Transmission success probability & $.1-1$ & $.1-1$ \\
\hline$N$ & No. vectors & Variable & Variable \\
\hline$H$ & No. hosts & Variable & Variable \\
\hline$m$ & Ratio of vectors to hosts & $N / H$ & $\mathrm{~N} / \mathrm{H}$ \\
\hline $\mathrm{iN}$ & No. infected vectors & Time dependent & Time dependent \\
\hline$a$ & Vector infection prevalence & $\mathrm{iN} / N$ & $\mathrm{iN} / N$ \\
\hline$b$ & Bites per vector per time step & 1 & $\begin{array}{c}\text { Dependent on monthly feeding } \\
\text { proportion, } q\end{array}$ \\
\hline$c$ & Infected bites received per host per time step & $a \times m \times b$ & $a \times m \times q$ \\
\hline $\operatorname{sti}_{\mathrm{H}}$ & $\begin{array}{l}\text { Probability of change from susceptible to } \\
\text { infected host }\end{array}$ & $1-\left[(1-r)^{c}\right]$ & $1-\left[(1-r)^{c}\right]$ \\
\hline JS & Juvenile survival per time step & .99217 & .92224 \\
\hline AS & Adult survival per time step & .99217 & .92224 \\
\hline \multirow[t]{3}{*}{$\mathrm{vt}$} & Probability of vertical transmission & Variable & Variable \\
\hline & & \multicolumn{2}{|c|}{ Both models } \\
\hline & & On annual time steps & All other time steps \\
\hline sJS & Susceptible juvenile survival & 0 & $\mathrm{JS} \times\left(1-\mathrm{sti}_{\mathrm{H}}\right)$ \\
\hline iJS & Infected juvenile survival & 0 & $\mathrm{JS} \times(1-R)$ \\
\hline rJS & Recovered juvenile survival & 0 & $\mathrm{JS} \times(1-f)$ \\
\hline sAS & Susceptible adult survival & 0 & $\mathrm{AS} \times\left(1-\mathrm{sti}_{\mathrm{H}}\right)$ \\
\hline iAS & Infected adult survival & 0 & AS $\times(1-R)$ \\
\hline rAS & Recovered adult survival & AS & AS $\times(1-f)$ \\
\hline sJtA & Susceptible juvenile to susceptible adult & $\mathrm{JS} \times\left(1-\mathrm{sti}_{\mathrm{H}}\right)$ & 0 \\
\hline iJtA & Infected juvenile to infected adult & $\mathrm{JS} \times(1-R)$ & 0 \\
\hline rJtA & Recovered juvenile to recovered adult & JS & 0 \\
\hline sJiJ & Susceptible juvenile to infected juvenile & 0 & $\mathrm{JS} \times \mathrm{sti}_{\mathrm{H}}$ \\
\hline sJiA & Susceptible juvenile to infected adult & $\mathrm{JS} \times \mathrm{sti}_{\mathrm{H}}$ & 0 \\
\hline sAiA & Susceptible adults to infected adults & 0 & $\mathrm{AS} \times \mathrm{sti}_{\mathrm{H}}$ \\
\hline iArA & Infected adults to recovered adults & 0 & $\mathrm{AS} \times R$ \\
\hline $\mathrm{iJrJ}$ & Infected juvenile to recovered juvenile & 0 & $\mathrm{JS} \times R$ \\
\hline iJrA & Infected juvenile to recovered adult & $\mathrm{JS} \times R$ & 0 \\
\hline rJsJ & Recovered juvenile to susceptible juvenile & 0 & $\mathrm{JS} \times f$ \\
\hline rJsA & Recovered juvenile to susceptible adult & $\mathrm{JS} \times f$ & 0 \\
\hline rAsA & Recovered adult to susceptible adult & AS $\times f$ & AS $\times f$ \\
\hline HP & Offspring per host per year & 4 & 0 \\
\hline iHPs & Susceptible offspring per infected host per year & $4 \times(1-v t)$ & 0 \\
\hline $\mathrm{iHPi}$ & Infected offspring per infected host per year & $4 \times \mathrm{vt}$ & 0 \\
\hline ncJS & Juvenile survival, noncompetent host & 0 & JS \\
\hline ncJtA & Juvenile to adult, noncompetent host & JS & 0 \\
\hline ncAS & Adult survival, noncompetent host & AS & AS \\
\hline
\end{tabular}

mov 2002; Randolph et al. 2002; see fig. 4). Larvae, nymphs, and adults feed once per year, and bites are spread equally across available hosts. Adult females produce 2,000 eggs after feeding and then die. We assume that larvae and nymphs of both sexes bite vertebrates but that adult males do not (Randolph 1998). Bites on infective hosts infect the vector with probability determined by a variable probability of transmission success, and vectors remain infected for life. Vector feeding is seasonal and peaks with juvenile host production (Randolph et al. 2002). This seasonal feeding profile is achieved by moving a proportion of the freeliving ticks of each stage (larvae, nymphs, adults) into respective separate fed stages (see fig. 4; table 3), according to

$$
\mathrm{FX}_{t+1}=X_{t} \times p
$$




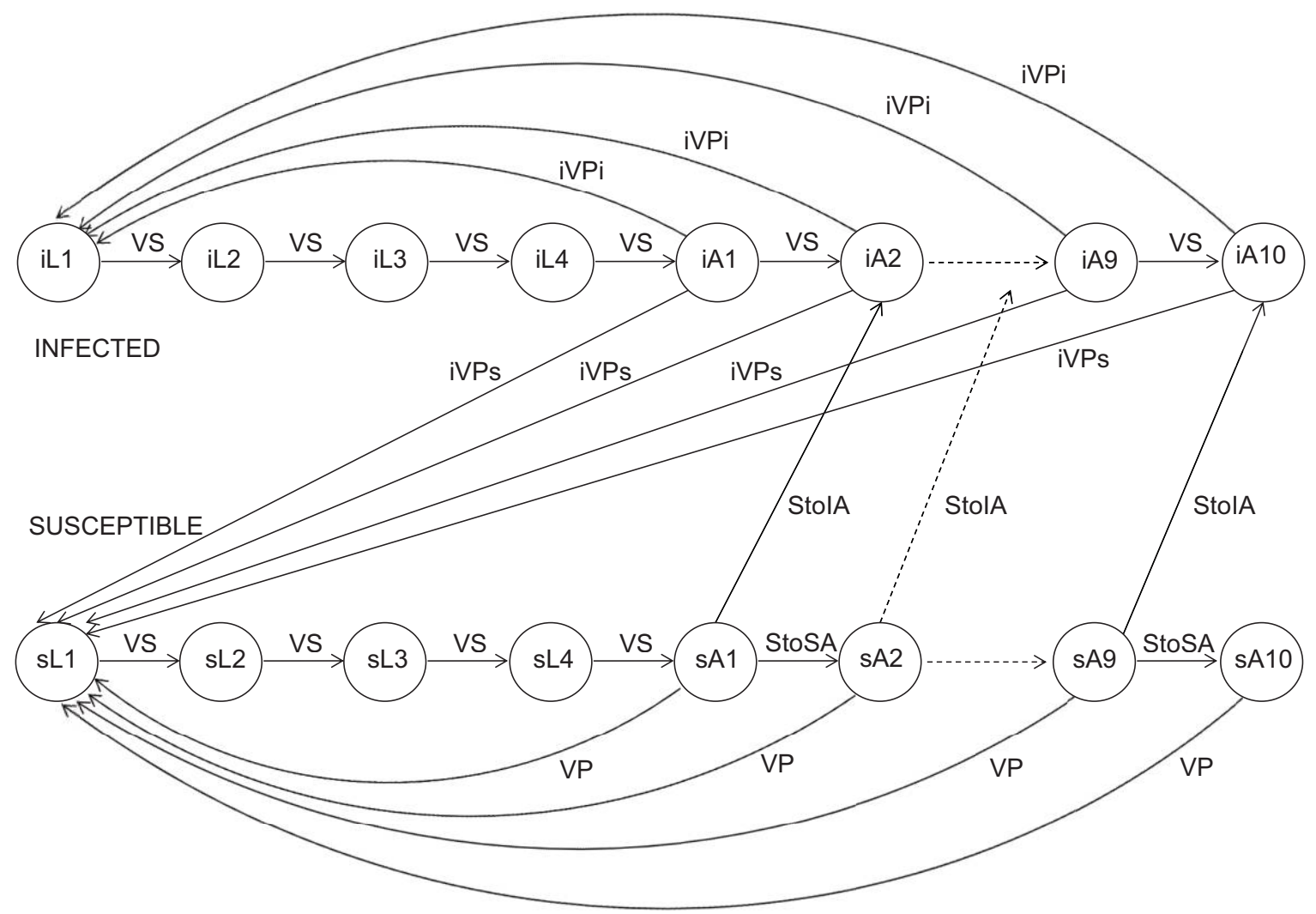

Figure 3: Flow diagram for the mosquito model. Individuals move between stages every 3 days. The stages (in circles) beginning with iL, iA, sL, and sA correspond to infected larvae, infected adults, susceptible larvae, and susceptible adults, respectively. The numbers denote the age class (each age class lasts 3 days); mosquitoes in this model, therefore, survive for $(4 \times 3) 12$ days as larvae and $(10 \times 3) 30$ days as adults. Definitions and values of the coefficients may be found in table 2 .

where $X$ is either larvae, nymphs, or adults, and FX is the fed individuals of the respective stage. The coefficient $p$ varies by month: in months $1-8, p=0.5$; in month $9, p=1$; and in months $10-12, p=0$. This gradual release of unfed ticks into the fed stages is such that $99.6 \%$ are fed by month 8 , and the peak is in month 1 , which is the month when the hosts reproduce. The infection of hosts in the tick model follows that of the mosquito model (eqq. [1]-[2]). The infection of ticks by hosts is similar to equation (3), with the exception that the right-hand side is multiplied by $p$. Equation

Table 2: Vector parameters for the mosquito model

\begin{tabular}{llc}
\hline Parameter & \multicolumn{1}{c}{ Definition } & Value \\
\hline$r$ & Transmission success probability & $.1-1$ \\
$\mathrm{iH}$ & No. infected hosts & Time dependent \\
$H$ & No. hosts & Variable \\
$b$ & Bites per vector per time step & 1 \\
$\mathrm{sti}_{\mathrm{v}}$ & Probability of change from susceptible to infected vector & $b \times r(\mathrm{iH} / H)$ \\
$\mathrm{vt}$ & Probability of vertical transmission & $0, .1$ \\
$\mathrm{VS}$ & Stage survival per time step & .39450503 \\
StoSI & Susceptible adults to infected adults & $\mathrm{sti}_{\mathrm{v}} \times \mathrm{VS}$ \\
StoSA & Stage survival (susceptible adults) & $\left(1-\mathrm{sti}_{\mathrm{v}}\right) \times \mathrm{VS}$ \\
VP & Offspring per vector per blood meal & 50 \\
iVPi & Infected offspring per infected vector per blood meal & $\mathrm{VP} \times \mathrm{vt}$ \\
iVPs & Susceptible offspring per infected vector per blood meal & $\mathrm{VP} \times(1-\mathrm{vt})$ \\
\hline
\end{tabular}




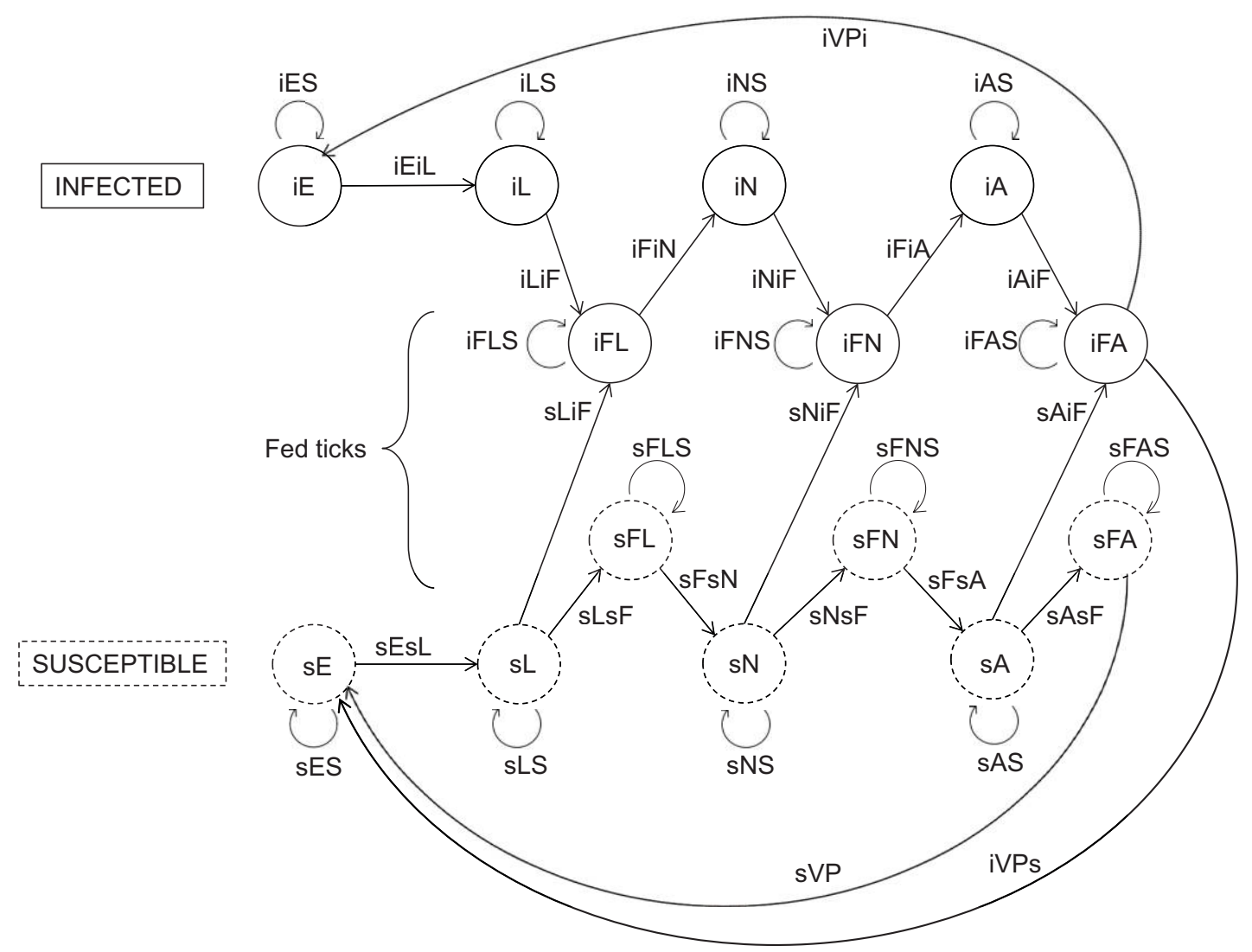

Figure 4: Flow diagram for the tick model. Individuals move between stages every month. The stages (in circles) iE, iL, iN, iA, sE, sL, sN, and sA correspond to infected eggs, larvae, nymphs, and adults and susceptible eggs, larvae, nymphs, and adults, respectively. Definitions and values of the coefficients may be found in table 3 .

(4), therefore, denotes the sum of fed ticks of each stageboth infected and uninfected.

In both models, the probability of mortality of all hosts and vectors is set to maintain population stability (Ogden and Tsao 2009). Results are insensitive to seeding conditions of infection prevalence in hosts and vectors; we start with an infection prevalence of 0.5 in both. Leslie matrices for all models are provided in the supplementary materials. Full R code for models, including graphics, is deposited in the Dryad Digital Repository: http://dx.doi.org/10.5061 /dryad.t24pq (Dobson and Auld 2016).

\section{Changes in Host Community Composition}

We investigated two types of biodiversity change in the host community: substitutive change, where half the competent hosts are replaced by noncompetent individuals while host population size remains constant; and additive change, where noncompetent hosts are added such that the host population doubles. We considered each of these changes under three different numerical relationships
(NR) between vectors and hosts: NR1, where vector abundance is independent of that of hosts and remains constant; NR2, where vector abundance increases linearly with that of hosts; and NR3, where vector abundance increases more than linearly with that of hosts, such that an eventual doubling of the host population results in a quadrupling of the vector population. (The level of vector increase in NR3 was chosen to provide symmetry with the scenario of additive change with NR1, where host population size doubles as vector numbers remain constant).

\section{Transmission Success and Host Recovery}

Transmission success probability varies between 0.1 and 1.0 , and host recovery probability varies between 0 and 0.045 (mosquito models) and 0 and 0.45 (tick models). The differing scales are due to the different time steps used in the two models; for comparison, the approximate midpoints 0.02 (mosquitoes) and 0.2 (ticks) result in $73.8 \%$ and $70.2 \%$, respectively, of hosts recovering from infection 
Table 3: Vector parameters for the tick model

\begin{tabular}{|c|c|c|c|}
\hline Parameter & Definition & \multicolumn{2}{|l|}{ Value } \\
\hline$p$ & Monthly feeding proportion & \multicolumn{2}{|c|}{ Months 1-8: .5; month 9: 1 ; months 10-12: 0} \\
\hline$r$ & Transmission success probability & \multicolumn{2}{|c|}{$.1-1$} \\
\hline$H$ & No. hosts & \multicolumn{2}{|l|}{ Variable } \\
\hline $\mathrm{iH}$ & No. infected hosts & \multicolumn{2}{|l|}{ Variable } \\
\hline E & Eggs per adult female per year & \multicolumn{2}{|c|}{2,000} \\
\hline ES & Egg survival per month & \multicolumn{2}{|c|}{$\left[1 / 1,000^{1 / 3}\right]^{1 / 12}$} \\
\hline LS & Larva survival per month & \multicolumn{2}{|c|}{$\left[1 / 1,000^{1 / 3}\right]^{1 / 12}$} \\
\hline NS & Nymph survival per month & \multicolumn{2}{|c|}{$\left[1 / 1,000^{1 / 3}\right]^{1 / 12}$} \\
\hline AS & Adult survival per month & \multicolumn{2}{|c|}{$\left[1 / 1,000^{1 / 3}\right]^{1 / 12}$} \\
\hline $\mathrm{sti}_{\mathrm{v}}$ & $\begin{array}{l}\text { Probability of change from susceptible to fed } \\
\text { infected vector }\end{array}$ & \multicolumn{2}{|c|}{$r \times(\mathrm{iH} / H) \times p$} \\
\hline $\operatorname{stn}_{\mathrm{v}}$ & $\begin{array}{l}\text { Probability of change from susceptible to fed } \\
\text { uninfected vector }\end{array}$ & \multirow{2}{*}{$\multicolumn{2}{|c|}{1-[r \times(\mathrm{iH} / H)]} \times p$} \\
\hline \multirow[t]{2}{*}{$\mathrm{vt}$} & \multirow[t]{2}{*}{ Probability of vertical transmission } & & \\
\hline & & On annual time steps [time steps] & All other time steps \\
\hline $\mathrm{iES}$ & Infected egg survival & $0[12]$ & ES \\
\hline sES & Susceptible egg survival & $0[12]$ & ES \\
\hline iLS & Infected larva survival & $\mathrm{LS} \times(1-p)$ & $\mathrm{LS} \times(1-p)$ \\
\hline sLS & Susceptible larva survival & $\mathrm{LS} \times(1-p)$ & $\mathrm{LS} \times(1-p)$ \\
\hline iNS & Infected nymph survival & $\mathrm{NS} \times(1-p)$ & $\mathrm{NS} \times(1-p)$ \\
\hline sNS & Susceptible nymph survival & $\mathrm{NS} \times(1-p)$ & $\mathrm{NS} \times(1-p)$ \\
\hline iAS & Infected adult survival & $\mathrm{AS} \times(1-p)$ & $\mathrm{AS} \times(1-p)$ \\
\hline sAS & Susceptible adult survival & AS $\times(1-p)$ & $\mathrm{AS} \times(1-p)$ \\
\hline iFLS & Fed, infected larva survival & $0[12]$ & LS \\
\hline sFLS & Fed, uninfected larva survival & $0[12]$ & LS \\
\hline iFNS & Fed, infected nymph survival & $0[12]$ & NS \\
\hline sFNS & Fed, uninfected nymph survival & $0[12]$ & NS \\
\hline iFAS & Fed, infected adult survival & $0[10,11,12]$ & AS \\
\hline sFAS & Fed, uninfected adult survival & $0[10,11,12]$ & AS \\
\hline iEiL & Infected egg to infected larva & ES [12] & 0 \\
\hline sEsL & Susceptible egg to susceptible larva & ES [12] & 0 \\
\hline sLiF & Susceptible larva to fed, infected larva & $0[12]$ & $\mathrm{LS} \times \mathrm{sti}_{\mathrm{v}}$ \\
\hline sLsF & Susceptible larva to fed, uninfected larva & $0[12]$ & $\mathrm{LS} \times \operatorname{stn}_{\mathrm{v}}$ \\
\hline iLiF & Infected larva to fed, infected larva & $0[12]$ & $\mathrm{LS} \times p$ \\
\hline $\mathrm{iFiN}$ & Fed, infected larva to infected nymph & LS [12] & 0 \\
\hline $\mathrm{sFsN}$ & Fed, uninfected larva to susceptible nymph & LS [12] & 0 \\
\hline $\mathrm{sNiF}$ & Susceptible nymph to fed, infected nymph & $0[12]$ & $\mathrm{NS} \times \mathrm{sti}_{\mathrm{v}}$ \\
\hline $\mathrm{sNsF}$ & Susceptible nymph to fed, uninfected nymph & $0[12]$ & $\mathrm{NS} \times \operatorname{stn}_{\mathrm{v}}$ \\
\hline $\mathrm{iNiF}$ & Infected nymph to fed, infected nymph & $0[12]$ & $\mathrm{NS} \times p$ \\
\hline iFiA & Fed, infected nymph to infected adult & NS [12] & 0 \\
\hline sFsA & Fed, uninfected nymph to susceptible adult & NS [12] & 0 \\
\hline sAiF & Susceptible adult to fed, infected adult & $0[10,11,12]$ & AS $\times \operatorname{sti}_{\mathrm{v}}$ \\
\hline sAsF & Susceptible adult to fed, uninfected adult & $0[10,11,12]$ & AS $\times \operatorname{stn}_{v}$ \\
\hline $\mathrm{iAiF}$ & Infected adult to fed, infected adult & $0[10,11,12]$ & $\mathrm{AS} \times p$ \\
\hline iVPi & Infected eggs per infected vector & $\mathrm{AS} \times E \times \mathrm{vt}[10]$ & 0 \\
\hline iVPs & Susceptible eggs per infected vector & $\mathrm{AS} \times E \times(1-\mathrm{vt})[10]$ & 0 \\
\hline sVP & Susceptible eggs per susceptible vector & $\mathrm{AS} \times E[10]$ & 0 \\
\hline
\end{tabular}

within 6 months. Empirical recovery rates vary between combinations of pathogen and host (Gitau et al. 1999; Hofmeister et al. 1999; Gu et al. 2003). We chose a realistic spread of values but acknowledge that certain hosts could clear infections at rates faster than we simulate. Within each model, the two community changes and three demographic relationships produce six possible scenarios. We present results for the 100 combinations of the 10 host recovery probabilities and 10 transmission success probabilities. As a default setting, we assumed no vertical transmis- 
sion (VT) in vectors or hosts, but we also present results showing effects of VT with a probability of 0.1 in hosts, vectors, or both. In our basic host model, recovered hosts cannot be reinfected (susceptible-infected-removed [SIR] model). However, we also performed simulations with an SIRS host infection cycle. In the SIRS models, recovered hosts returned to the susceptible state 1 month after recovery. For mosquito models, which move in three daily time steps, we adjusted the probability of moving from recovered to susceptible such that $99 \%$ of recovered hosts were susceptible within 1 month.

\section{Simulations}

All model runs were initiated with 10 years of no host change to ensure infection equilibria had been reached, after which the host community change was introduced. Models were run for a further 20 years to ensure postchange equilibria were reached. Transmission success and host recovery probabilities were set at the start of each simulation. Infection parameters were taken as annual means from the final year of simulation (equilibrium always having been reached before this point).

\section{Model Assumptions}

Some of the assumptions in these models reflect the general nature of the study, which is not designed to investigate the dynamics of any specific disease system. First, we do not assume any host preference among vectors. This may be unrealistic for most mosquitoes, meaning that our models may predict transmission interference - and, hence, dilution-too readily (but see Smith et al. 2007). For ticks, the assumption is more robust, since contact with hosts is often largely opportunistic; free-living ticks (as opposed to those that live in host burrows), in particular, feed on a wide variety of host species (Gray 1998). Even among vectors that are able to choose their hosts, host preference will not necessarily increase transmission to the most competent hosts, so the epidemiological consequences will not be universally consistent (but see Smallegange et al. 2013). Further simplifying assumptions are as follows: (i) Infection does not reduce host or vector fitness. (ii) There is no superinfection; that is, the recovery of infected hosts is not delayed by subsequent infectious bites. (iii) Infection does not alter vector behavior, although this does occur for some pathogen/vector combinations (Auld and Tinsley 2015; but see Cator et al. 2013). (iv) There are no density-dependent thresholds of vector-host ratio, though this can occur if hosts respond to high vector densities by increased grooming behavior and/or immune response to bites (Levin and Fish 1998; Darbro and Harrington 2007; but see also Charlwood et al. 1995). Removal of this as- sumption would require knowledge of thresholds. Given the absence of supporting data, we assume no thresholds, and we do not simulate high numbers of vectors per host (see references above for empirical figures). If such responses were to occur, the result would be to cause a leveling off in the relationship between vector density and strength of amplification at high vector densities. For our models, this would affect only the NR3 scenarios. (v) Per-vector biting probabilities are not limited at high or low host densities (the main characteristic of reservoir frequency dependence, a specific variant of FD transmission; see Wonham et al. 2006 for implications and further definitions). (vi) Host-tovector and vector-to-host transmission success probabilities (the probability that contact between one infected individual and one noninfected individual results in infection of the latter) are equal.

\section{Results \\ Change in Density of Infected Vectors}

For both types of vector, epidemiological outcomes resulting from changes in host community composition depended strongly on an interaction between the nature of host community change (additive or substitutive) and the numerical relationship between vector and host. When the host change was substitutive, DIV was always diluted. Under additive host change, dilution was most likely where vector numbers were independent of host numbers (NR1) and where initial infection prevalence in vectors was lowest. Amplification was most likely where vector density increased at a greater rate than host density (NR3) and where infection prevalence was initially highest (figs. 5, 6). Amplification was also a more frequent outcome in mosquito models than tick models. This difference was maintained across all vectorhost ratios tested (see figs. S5-S7, S11-S13; figs. S1-S28 available in the supplementary material).

\section{Change in the Proportion of Infected Hosts}

Dilution was more likely when measured as PIH as opposed to DIV, although at very high transmission success probabilities, dilution was either absent or negligible in all scenarios (fig. 7). Differences between vectors followed the pattern seen in DIV plots and were maintained across all vector-host ratios tested (see figs. S8-S10, S14-S16).

\section{Vertical Transmission, Reinfection, and Altered Vector-Host Ratios}

The inclusion of vertical transmission and host reinfection resulted in different disease outcomes in mosquito and tick models. Most differences between our sets of simulations 

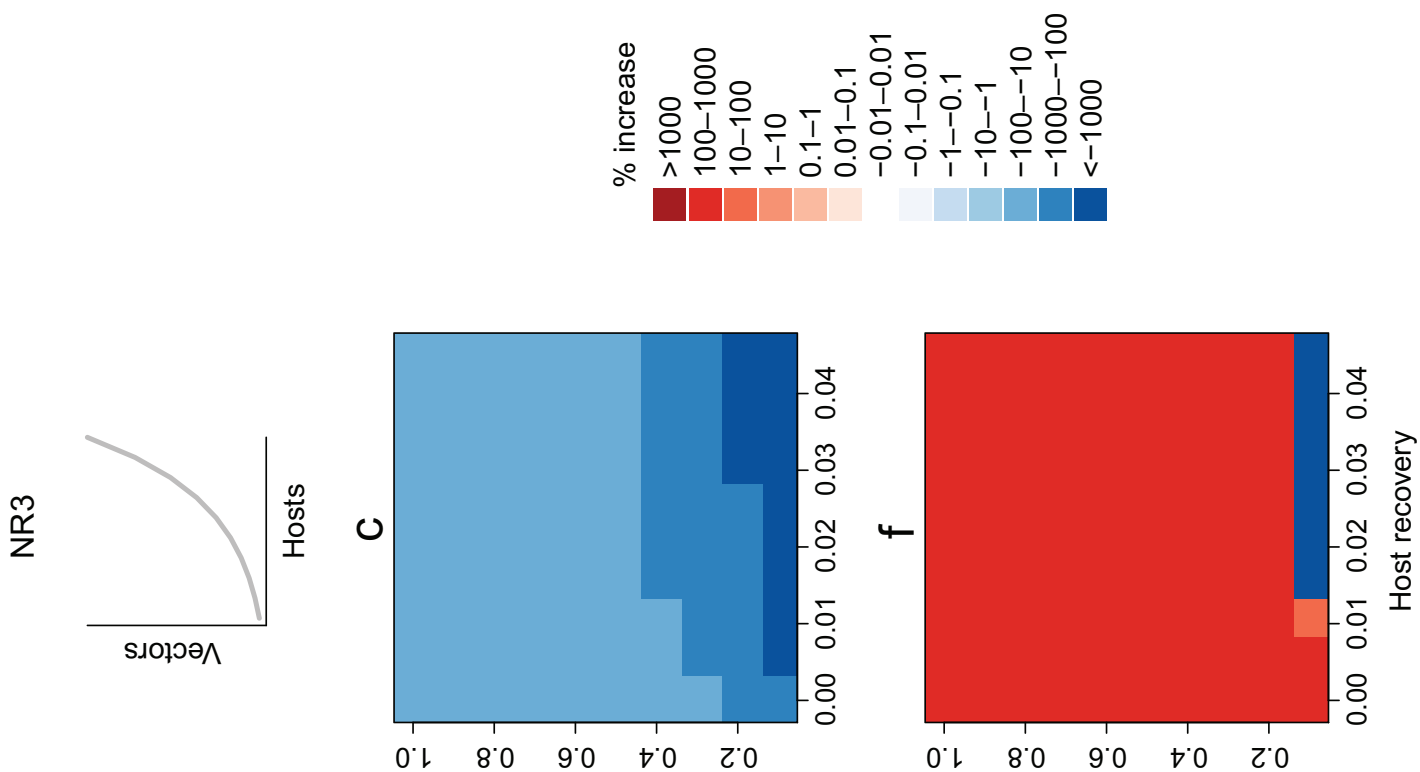

吾
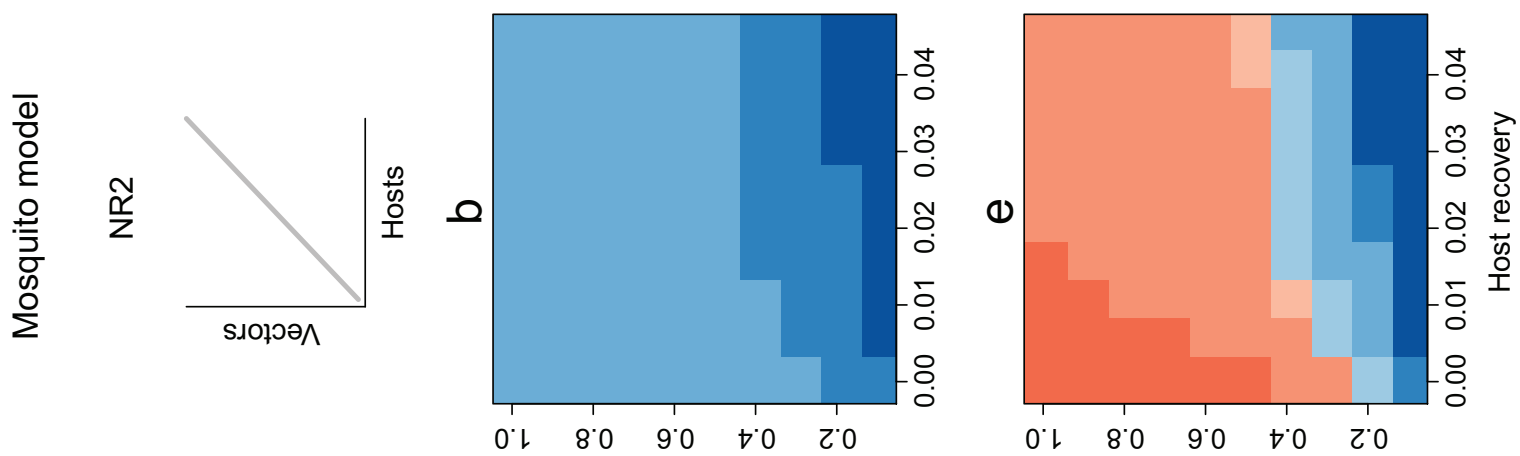

党官
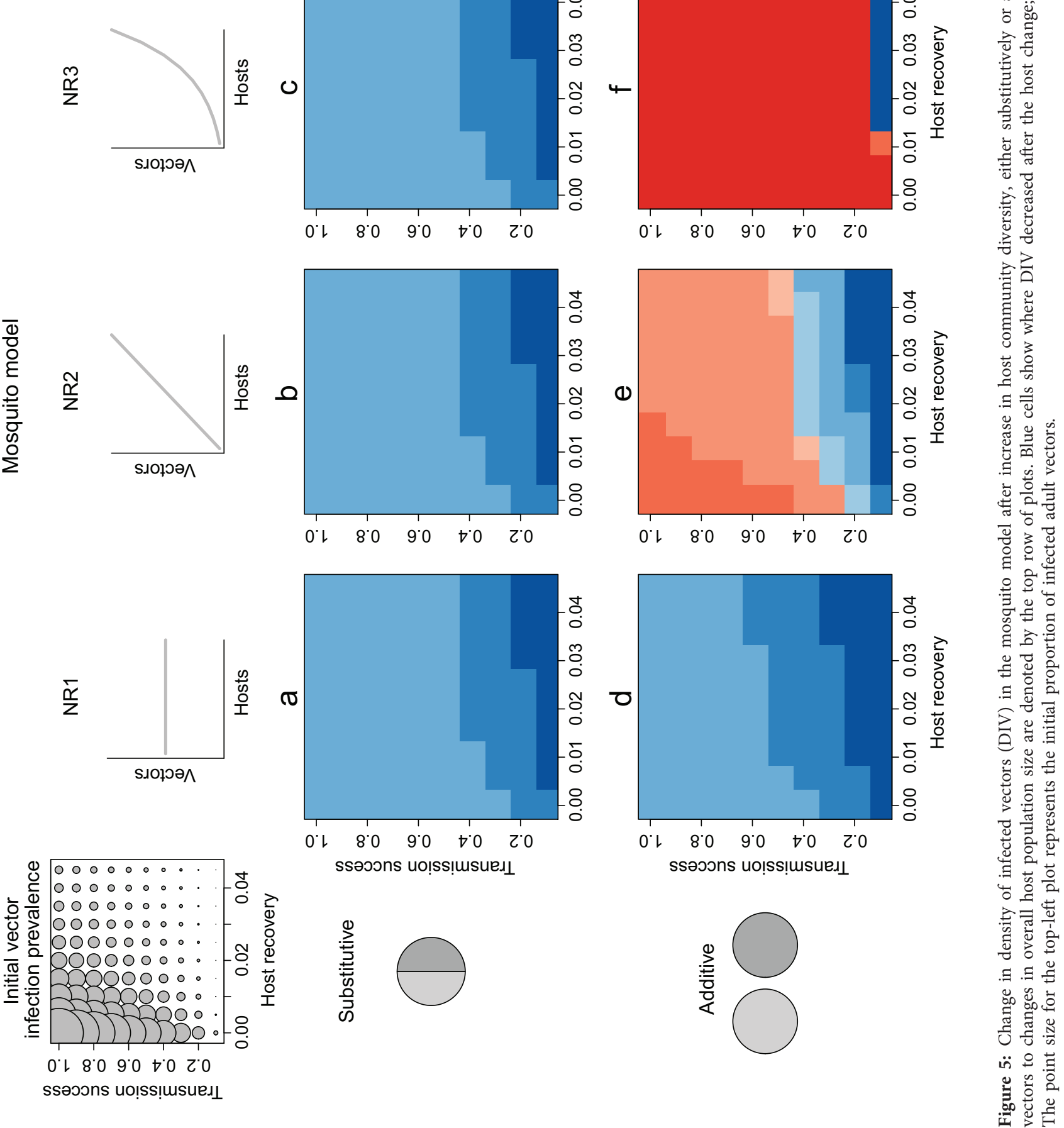


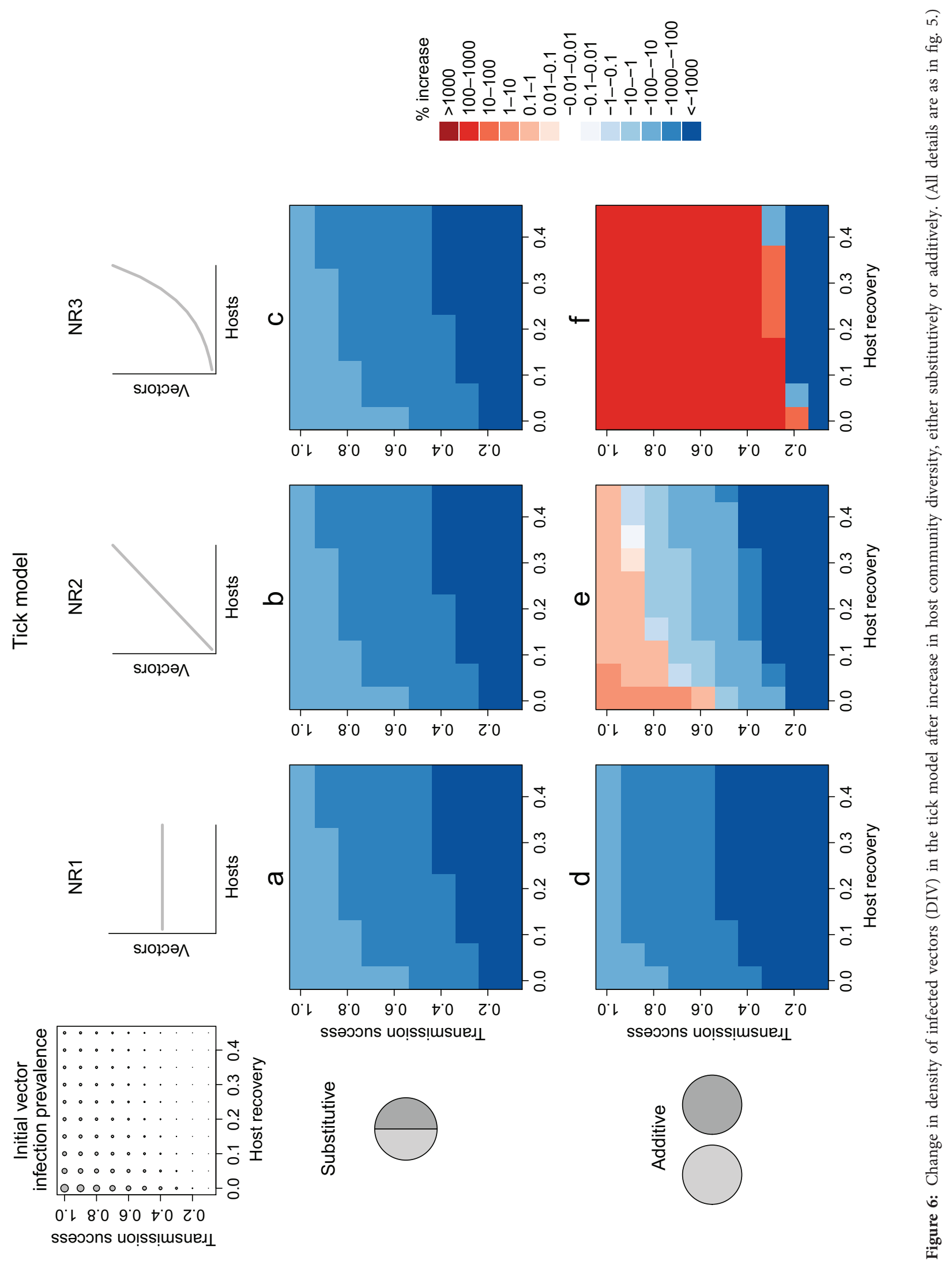



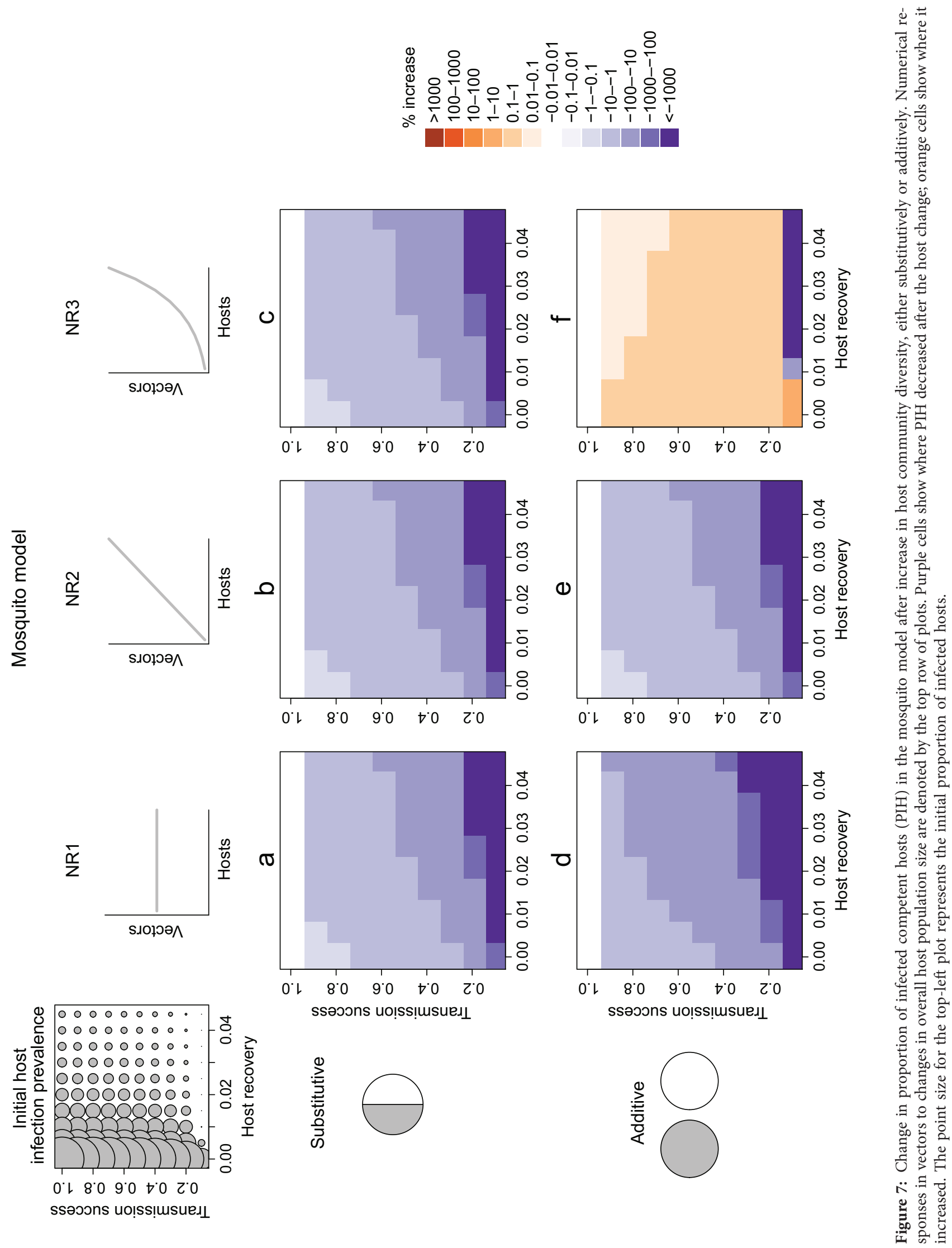

This content downloaded from 139.153.095.163 on March 01, 2016 01:52:17 AM 
are found in the plots showing the additive NR2 scenario, so for simplicity, we focus on these plots (see supplementary material for figures for all VT and reinfection simulations, figs. S21-S28). Table 4 shows the number of cells in centerbottom DIV and PIH plots that switched between dilution and amplification. Switches caused by VT were recorded only in DIV and almost entirely found in the tick plots (44/45). All were of dilution switching to amplification (fig. 8). VT in hosts caused no switches. Host reinfection had a smaller impact, triggering only five switches among the four pairs of plots (table 4). Altering the vector-host ratio had predictable effects on epidemiological parameters: rather than changing the character of the overall result, it instead shifted the threshold values of transmission success and recovery probabilities that determined the switch between amplification and dilution. The vector-host ratio was broadly proportional to the likelihood of amplification (see figs. S5-S16).

\section{Discussion}

Vector biology necessarily underpins VBD transmission (Randolph 1998), and yet it is given scant consideration in many disease models. Our simple yet general models incorporate important differences between ticks and mosquitoes in terms of their biting rates, reproductive biology, and responses to numeric changes in the host community. These differences confirm the importance of explicitly considering vectors in models of VBD and provide more nuanced insights into the possible outcomes of environmental change.

VBD transmission is usually assumed to be frequency dependent (e.g., Wonham et al. 2004; Joseph et al. 2013; Roche et al. 2013). However, some of the predictions that follow from the assumption of FD transmission may hold only for directly transmitted diseases and not VBDs (Dobson 2004). For example, while our NR3 scenario is underpinned by the same FD transmission term as the others, the func- tion is essentially $\mathrm{DD}$, since the ratio of vectors to hosts (and, therefore, the bites per host) increases with host density (Ogden and Tsao 2009).

The term vector amplification is used to describe the situation whereby an increase in host abundance triggers a related rise in vector numbers (regardless of infection prevalence). Vector amplification can cause increases in overall vector density that balance - or, in some cases, outweighany reductions in vector infection prevalence following biodiversity increase. Wood et al. (2014) use the term "spurious dilution" to describe such reductions in infection prevalence that nonetheless do not reduce overall disease risk. The mechanics and implications of this phenomenon have been much discussed elsewhere (e.g., Norman et al. 1999; Dobson 2004; Ostfeld and Keesing 2012; Randolph and Dobson 2012), and we do not dwell on it here. However, we emphasize the more subtle difference between vector amplification and the situation whereby vector abundance increases more than linearly with that of hosts (i.e., NR3; Randolph and Dobson 2012), shifting the transmission function from FD to DD.

Many authors have recognized that under additive host change, DD transmission should cause increased disease risk (e.g., Dobson 2004; Ostfeld and Keesing 2012). Our models highlight situations where amplification follows from more strictly FD transmission. In our pair of models, additive host change and FD transmission causes amplification of DIV (under certain combinations of transmission success and host recovery probabilities). Previous models have suggested that amplification ought not to occur when transmission is FD, even when the host change is additive (Rudolf and Antonovics 2005; Mihaljevic et al. 2014). Indeed, if one considers only PIH (the prevalence of infection in hosts), it does not (note that the NR3 scenario is not strictly FD). However, an increase in DIV can occur because individual vectors bite both types of host. Bites on noncompetent hosts are wasted, but the vector may still become infected later if it subsequently feeds on an infected host, in

Table 4: Impacts of the addition of vertical transmission in vectors and reinfection of recovered hosts for plots of density of infected vectors (DIV) and proportion of competent infected hosts $(\mathrm{PIH})$ in mosquito and tick models

\begin{tabular}{|c|c|c|c|c|}
\hline \multirow[b]{2}{*}{ Impact, model } & \multicolumn{2}{|c|}{ Cells switching in DIV plot } & \multicolumn{2}{|c|}{ Cells switching in PIH plot } \\
\hline & $\begin{array}{l}\text { Dilution to } \\
\text { amplification }\end{array}$ & $\begin{array}{l}\text { Amplification } \\
\text { to dilution }\end{array}$ & $\begin{array}{l}\text { Dilution to } \\
\text { amplification }\end{array}$ & $\begin{array}{c}\text { Amplification } \\
\text { to dilution }\end{array}$ \\
\hline \multicolumn{5}{|c|}{ Impact of vertical (vectorial) transmission: } \\
\hline Mosquito & 1 & 0 & 0 & 0 \\
\hline Tick & 44 & 0 & 0 & 0 \\
\hline \multicolumn{5}{|c|}{ Impact of host reinfection: } \\
\hline Mosquito & 2 & 0 & 0 & 0 \\
\hline Tick & 2 & 1 & 0 & 0 \\
\hline
\end{tabular}



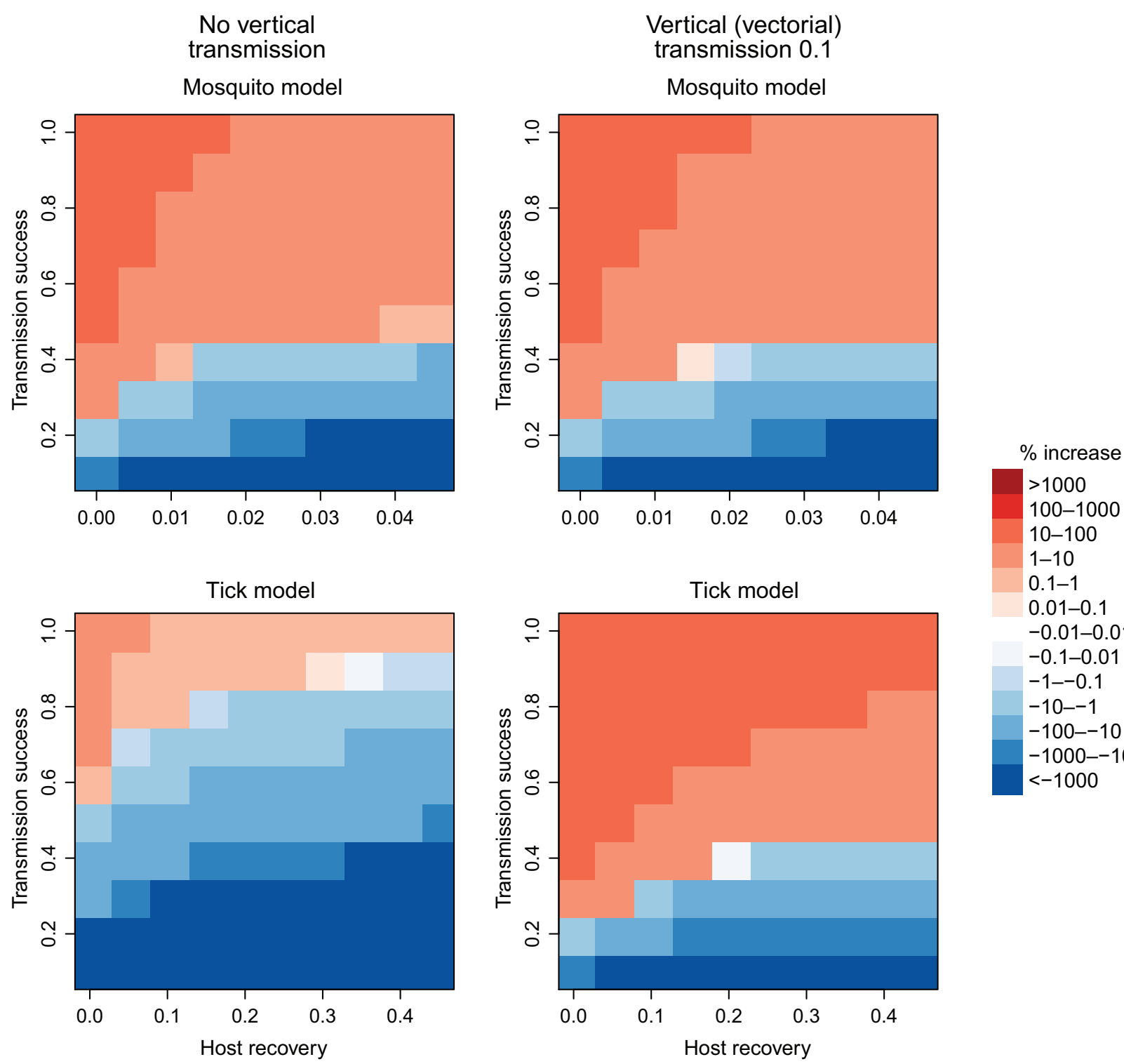

$1-10$

$0.1-1$

0.01-0.1

$-0.01-0.01$

$-0.1-0.01$

$-1--0.1$

$-10--1$

$-100--10$

$-1000--100$

$<-1000$

Figure 8: Impact of vertical (within vectors) transmission on change in density of infected vectors. Upper plots, mosquitoes: comparison of figure $5 e$ (left) with the same output from a model with vertical transmission in vectors with a probability of 0.1 (right). Lower plots, as previous but for ticks (fig. $6 e$ ).

which case the earlier wasted bite is largely irrelevant. Consider, for simplicity, a vector that bites $b$ hosts in its lifetime and bites hosts at random in a population where there is a static host infection prevalence of $x$. The chance of the vector acquiring an infection during its lifetime is not $x$ but

$$
1-(x-1)^{b} .
$$

In reality, the value of $x$ is not static and instead will change as hosts recover or become infected, but it is nonetheless clear that the chance of any individual vector acquiring an infection must increase with the total number of hosts, $b$. A halving of the proportion of competent hosts does not, therefore, lead to a halving of infection prevalence in vectors (fig. 1B). In our models with FD transmission and additive change, dilution occurs only when transmission success falls below a certain threshold, because the probability that a wasted bite will prevent a vector from ever being infected declines as transmission success increases.

A consistent result to emerge from our models is that the higher the initial infection prevalence - correlated in these models with the product of transmission success probability 
and $1 /$ (host recovery probability) - the less likely dilution of DIV is to result from either sort of biodiversity increase (additive or substitutive). When vectors bite several times, many bites will be from infected vectors on infected hosts. From an epidemiological perspective, these bites are equally wasted as when infected vectors bite nonsusceptible hosts (Smith et al. 2007). It follows, therefore, that the proportion of diseasecarrying vectors may decline without affecting the rate at which susceptible hosts become infected. Susceptible hosts receive fewer bites, but as long as this number is above the threshold required to transmit an infectious dose of the pathogen, it is of little consequence. Similarly, if hosts rarely recover from infection, any genuinely wasted bites (infective bites on noncompetent hosts) are less critical for maintenance of disease prevalence, because the total number of infective bites required to retain a reservoir of infectious hosts remains low. This finding is important because it implies that dilution occurs most readily where infection risk is low (i.e., low transmission success and rapid host recovery). Further, these results were robust to changes in the ability of recovered hosts to become reinfected.

Vertical transmission can provide an additional mechanism through which the effects of biodiversity change differ between MBDs and TBDs. The epidemiological consequences of vertical transmission were greater for tick-borne infections than for mosquito-borne infections. The mechanism underlying this is related to the differing rates of feeding: mosquitoes (in these models) will feed up to 10 times, whereas the ticks can feed only three times (in line with real biological differences between the vectors; Randolph 1998). The mosquito, therefore, has more opportunities to acquire infection (see eq. [1]), meaning that the potential for DIV and/or PIV to be increased by one extra infection opportunity (i.e., through maternal inheritance of the pathogen) is lower for mosquitoes than for ticks.

It follows that, all other factors being equal, the likelihood of dilution declines as the number of vectors per host decreases. From this observation, one might assume dilution to be less likely in MBDs than in TBDs, since individual ticks typically bite fewer hosts than do individual mosquitoes (Randolph 1998). However, ticks may consistently differ in the way that they respond numerically to increases in host density. As discussed above, if a vector increases more than linearly with increases in host density, disease amplification becomes more likely. This scenario (NR3, in our models) is probably uncommon for mosquitoes, since their greater mobility (relative to ticks) means that their probability of encountering a host is less determined by host density, but is theoretically almost inevitable for ticks, at least below any thresholds of per-host tick loads that might cause a density-dependent response to parasitism in hosts (Ogden and Tsao 2009; Dobson 2014). Mosquitoes and related vectors are more likely to fit into the NR1 or NR2 sce- nario. However, while the NR1 response may be common among mosquitoes, dilution may not be as prevalent as our models suggest; the dilution predicted here is via transmission interference, which relies on the assumption that vectors have no preference between competent and noncompetent hosts. As already mentioned, mosquitoes may preferentially bite competent hosts, thereby reducing transmission interference and, hence, the potential strength of dilution.

Different metrics are used to describe disease outcomes in the literature, for example, PIV, DIV, and PIH (Salkeld et al. 2013). Our results demonstrate that these metrics are not interchangeable. The different implications of changes in PIV and DIV are frequently discussed, but we also reveal here the subtly divergent behavior of DIV and PIH: it is possible for a rise in DIV to occur simultaneously with a decline in PIH, even without exponential vector population increase (cf. figs. $5 e$ and $7 e$ ). Note that this is quite separate from what Wood et al. (2014) describe as "spurious dilution" - the situation of declining PIV (not PIH) with increasing DIV, which is already well recognized (e.g., van Buskirk and Ostfeld 1995). The nature of the disease system will determine which metric is most relevant: where humans are one of the main hosts (e.g., malaria or dengue), a drop in PIH might be as important as a drop in DIV, but for zoonoses, where humans are only occasional, spillover hosts (e.g., Lyme borreliosis or West Nile virus), $\mathrm{PIH}$ is only indirectly relevant. Our finding that FD transmission need not prevent DIV amplification from occurring is particularly pertinent in this context.

Our modeling approach provides a generic framework for characterizing the consequences of vector biology on the biodiversity-prevalence relationship. We did not aim to produce a set of specific predictions for combinations of disease systems and conditions under which dilution or amplification ought to occur-our aim was to instead build a foundation on which more tailored models can be built to explore individual VBD systems. To this end, we have deliberately avoided providing quantitative results, as doing so would be claiming a false accuracy. We also remind readers that additive and substitutive host changes lie at extremes of a continuum and that disease outcomes in complex communities are unlikely to follow simple rules (e.g., Roche et al. 2013; Mihaljevic et al. 2014). Our results have, however, clearly demonstrated that modeling FD transmission without explicitly considering the vector can limit model applicability to real-world VBD systems.

\section{Acknowledgments}

We thank S. Randolph for helpful comments and corrections and S. Lindsay for information on mosquito-host ra- 
tios. Three anonymous reviewers and the associate editor provided constructive criticism that led to a greatly improved manuscript. A.D.M.D. is supported by an Impact Research Fellowship from the University of Stirling. S.K.J.R.A. is supported by a Natural Environment Research Council Independent Research Fellowship (NE/L011549/1).

\section{Literature Cited}

Allan, B. F., R. B. Langerhaus, W. A. Ryberg, W. J. Landesman, N. W. Griffin, R. S. Katz, B. J. Oberle, et al. 2009. Ecological correlates of risk and incidence of West Nile virus in the United States. Oecologia (Berlin) 158:699-708.

Auld, S. K. J. R., and M. C. Tinsley. 2015. The evolutionary ecology of complex lifecycle parasites: linking phenomena with mechanisms. Heredity 114:125-132.

Belozerov, V. N., and R. L. Naumov. 2002. Nymphal diapause and its photoperiodic control in the tick Ixodes scapularis (Acari: Ixodidae). Folia Parasitologica 49:314-318.

Bhatt, S., P. W. Gething, O. J. Brady, J. P. Messina, A. W. Farlow, C. L. Moyes, J. M. Drake, et al. 2013. The global distribution and burden of dengue. Nature 496:504-507, http://dx.doi.org/10.1038/na ture12060.

Brown, C. R., and R. A. Sethi. 2002. Mosquito abundance is correlated with cliff swallow (Petrochelidon pyrrhonota) colony size. Journal of Medical Entomology 39:115-120.

Campbell-Lendrum, D., L. Manga, M. Bagayoko, and J. Sommerfeld. 2015. Climate change and vector-borne diseases: what are the implications for public health research and policy? Philosophical Transactions of the Roval Society B: Biological Sciences 370:20130552, http://dx.doi.org/10.1098/rstb.2013.0552.

Carpi, G., F. Cagnacci, M. Neteler, and A. Rizzoli. 2008. Tick infestation on roe deer in relation to geographic and remotely sensed climatic variables in a tick-borne encephalitis endemic area. Epidemiology and Infection 136:1416-1424.

Cator, L. J., J. George, S. Blanford, C. C. Murdock, T. C. Baker, A. F. Read, and M. B. Thomas. 2013. "Manipulation" without the parasite: altered feeding behaviour of mosquitoes is not dependent on infection with malaria parasites. Proceedings of the Roval Society B: Biological Sciences 280:20130711.

Charlwood, J. D., T. Smith, J. Kihonda, B. Heiz, P. F. Billingsley, and W. Takken. 1995. Density-independent feeding success of malaria vectors (Diptera: Culicidae) in Tanzania. Bulletin of Entomological Research 85:29-35.

Darbro, J. M., and L. C. Harrington. 2007. Avian defensive behavior and blood-feeding success of the West Nile vector mosquito, $\mathrm{Cu}$ lex pipiens. Behavioural Ecology 18:750-757.

Dobson, A. 2004. Population dynamics of pathogens with multiple host species. American Naturalist 164(suppl):S64-S78.

Dobson, A. D. M. 2014. History and complexity in tick-host dynamics: discrepancies between "real" and "visible" tick populations. Parasites and Vectors 7:231.

Dobson, A. D. M., and S. K. J. R. Auld. 2016. Data from: Epidemiological implications of host biodiversity and vector biology: key insights from simple models. American Naturalist, Dryad Digital Repository, http://dx.doi:10.5061/dryad.t24pq.

Dobson, A. D. M., T. J. R. Finnie, and S. E. Randolph. 2011. A modified matrix model to describe the seasonal population ecology of the European tick Ixodes ricinus. Lournal of Applied Ecology 48: 1029-1037.

Dobson, A. D. M., and S. E. Randolph. 2011. Modelling the effects of recent changes in climate, host density and acaricide treatments on population dynamics of Ixodes ricinus in the UK. Iournal of Applied Ecology 48:1017-1028.

Duncan, J. S., H. W. Reid, R. Moss, J. D. P. Phillips, and A. Watson. 1978. Ticks, louping ill and red grouse on moors in Speyside, Scotland. Journal of Wildlife Management 42:500-505.

Gitau, G. K., B. D. Perry, and J. J. McDermott. 1999. The incidence, calf morbidity and mortality due to Theileria parva infections in smallholder dairy farms in Murang'a District, Kenya. Preventative Veterinary Medicine 39:65-79.

Gray, J. S. 1998. The ecology of ticks transmitting Lyme borreliosis. Experimental and Applied Acarology 22:249-258.

Gu, W., G. F. Killeen, C. M. Mbogo, J. L. Regens, J. I. Githure, and J. C. Beier. 2003. An individual-based model of Plasmodium falciparum malaria transmission on the coast of Kenya. Transactions of the Roval Society of Tropical Medicine and Hygiene 97:43-50.

Guernier, V., M. E. Hochberg. and J.-F. Guégan. 2004. Ecology drives the worldwide distribution of human diseases. PLoS Biology 2:e141, http://dx.doi.org/10.1371/journal.pbio.0020141.

Haas, S. E., M. B. Hooten, D. M. Rizzo, and R. K. Meentemeyer. 2011. Forest species diversity reduces disease risk in a generalist plant pathogen invasion. Ecology Letters 14:1108-1116.

Harvell, C. D., C. E. Mitchell, J. R. Ward, S. Altizer, A. P. Dobson, R. S. Ostfeld, and M. D. Samuel. 2002. Climate warming and disease risks for terrestrial and marine biota. Science 296:2158-2162.

Hay, S. I., E. A. Okiro, P. W. Gething, A. P. Patil, A. J. Tatem, C. A. Guerra, and R. W. Snow. 2010. Estimating the global clinical burden of Plasmodium falciparum malaria in 2007. PLoS Medicine 7: e1000290, http://dx.doi.org/10.1371/journal.pmed.1000290.

Hofmeister, E. K., B. A. Ellis, G. E. Glass, and J. E. Childs. 1999. Longitudinal study of infection with Borrelia burgdorferi in a population of Peromyscus leucopus at a Lyme disease-enzootic site in Maryland. American Journal of Tropical Medicine and Hygiene 60:598-609.

Johnson, P. T. J., P. J. Lund, R. B. Hartson, and T. P. Yoshino. 2009. Community diversity reduces Schistosoma mansoni transmission, host pathology and human infection risk. Proceedings of the Roval Society B: Biological Sciences 276:1657-1663.

Johnson, P. T. J., D. L. Preston, J. T. Hoverman, and K. L. D. Richgels. 2013. Biodiversity decreases disease through predictable changes in host community competence. Nature 494:230-234.

Joseph, M. B., J. R. Mihaljevic, S. A. Orofske, and S. H. Paull. 2013. Does life history mediate changing disease risk when communities disassemble? Ecology Letters 16:1405-1412.

Keesing, F., L. K. Belden, P. Daszak, A. Dobson, C. D. Harvell, R. D. Holt, P. Hudson, A. Jolles, K. E. Jones, C. E. Mitchell, S. S. Myers, T. Bogich, and R. S. Ostfeld. 2010. Impacts of biodiversity on the emergence and transmission of infectious diseases. Nature 468: $647-652$.

Keesing, F., R. D. Holt, and R. S. Ostfeld. 2006. Effects of species diversity on disease risk. Ecology Letters 9:485-498.

Kelly, D. W., and C. E. Thompson. 2000. Epidemiology and optimal foraging: modelling and the ideal free distribution of insect vectors. Parasitology 120:319-327.

Kilpatrick, A. M., and S. E. Randolph. 2012. Drivers, dynamics, and control of emerging vector-borne zoonotic diseases. Lancet 380: 1946-1955. 
Lacroix, C., A. Jolles, E. W. Seabloom, A. G. Power, C. E. Mitchell, and E. T. Borer. 2014. Non-random biodiversity loss underlies predictable increases in viral disease prevalence. Journal of the Roval Societv Interface 11:20130947, http://dx.doi.org/10.1098 /rsif.2013.0947.

Lafferty, K. D., and C. L. Wood. 2013. It's a myth that protection against disease is a strong and general service of biodiversity conservation: response to Ostfeld and Keesing. Trends in Ecology and Evolution 28:503-504.

Levin, M. L., and D. Fish. 1998. Density-dependent factors regulating feeding success of Ixodes scapularis larvae (Acari: Ixodidae) Journal of Parasitology 84:36-43.

LoGiudice, K., S. T. K. Duerr, M. J. Newhouse, K. A. Schmidt, M. E. Killilea, and R. S. Ostfeld. 2008. Impact of host community composition on Lyme disease risk. Ecology 89:2841-2849.

LoGiudice, K., R. S. Ostfeld, K. A. Schmidt, and F. Keesing. 2003. The ecology of infectious disease: effects of host diversity and community composition on Lyme disease risk. Proceedings of the National Academv of Sciences of the USA 100:567-571.

Matuschka, F.-R., P. Fischer, M. Heiler, D. Richter, and A. Spielman. 1992. Capacity of European animals as reservoir hosts for the Lyme disease spirochete. Journal of Infectious Diseases 165:479-483.

Matuschka, F.-R., P. Fischer, K. Musgrave, D. Richter, and A. Spielman. 1991. Hosts on which nymphal Ixodes ricinus most abundantly feed. American Journal of Tropical Medicine and $\mathrm{Hv}$ giene 44:100-107.

Matuschka, F.-R., and A. Spielman. 1986. The emergence of Lyme disease in a changing environment in North America and central Europe. Experimental and Applied Acarology 2:337-353.

Mbogo, C. M., J. M. Mwangangi, J. Nzovu, W. Gu, G. Yan, J. T. Gunter, C. Swalm, et al. 2003. Spatial and temporal heterogeneity of Anopheles mosquitoes and Plasmodium falciparum transmission along the Kenyan coast. American Journal of Tropical Medicine and Hygiene 68:734-742.

McLaughlin, R. E., and M. F. Vidrine. 1988. Psorophora columbiae larval density in southwestern Louisiana rice fields as a function of cattle density. Journal of the American Mosquito Control Association 3:633-635.

Mihaljevic, J. R., M. B. Joseph, S. A. Orlofske, and S. H. Paull. 2014. The scaling of host density with richness affects the direction, shape, and detectability of diversity-disease relationships. PLoS ONE 9(5):e97812, http://dx.doi.org/10.1371/journal.pone.0097812.

Minikawa, N., P. Seda, and G. Yan. 2002. Influence of host and larval habitat distribution on the abundance of African malaria vectors in western Kenya. American Journal of Tropical Medicine and Hygiene 67:32-38.

Norman, R., R. G. Bowers, M. Begon, and P. J. Hudson. 1999. Persistence of tick-borne virus in the presence of multiple host species: tick reservoirs and parasite-mediated competition. Lournal of Theoretical Biology 200:111-118.

Ogden, N. H., and J. I. Tsao. 2009. Biodiversity and Lyme disease: dilution or amplification? Epidemics 1:196-206.

Ostfeld, R. S. 2013. A Candide response to Panglossian accusations by Randolph and Dobson: biodiversity buffers disease. Parasitology 140:1196-1198.

Ostfeld, R. S., and F. Keesing. 2000. The function of biodiversity in the ecology of vector-borne zoonotic diseases. Canadian Journal of Zoology 78:2061-2078.

2012. Effects of host diversity on infectious disease. Annua Review of Ecology, Evolution and Systematics 43:157-182.
2013. Straw men don't get Lyme disease: response to Wood and Lafferty. Trends in Ecology and Evolution 28:502-503.

Paaijmans, K. P., M. O. Wandago, A. K. Githeko, and W. Takken. 2007. Unexpected high losses of Anopheles gambiae larvae due to rainfall. PLoS ONE 2(11):e1146, http://dx.doi.org/10.1371/journal .pone.0001146.

Parham, P. E., J. Waldock, G. K. Christophides, D. Hemming, F. Agusto, K. J. Evans, N. Fefferman, et al. 2015. Climate, environmental and socio-economic change: weighing up the balance in vector-borne disease transmission. Philosophical Transactions of the Roval Society B: Biological Sciences 370:20130551. http:// dx.doi.org/10.1098/rstb.2013.0551.

Pongsiri, M. J., J. Roman, V. O. Ezenwa, T. L. Goldberg, H. S. Koren, S. C. Newbold, R. S. Ostfeld, S. K. Pattanayak, and D. J. Salkeld. 2009. Biodiversity loss affects global disease ecology. BioScience 59:945-954.

Randolph, S. E. 1994. Population dynamics and density-dependent seasonal mortality indices of the tick Rhipicephalus appendiculatus in east and southern Africa. Medical and Veterinary Entomology 8: 351-368.

1998. Ticks are not insects: consequences of contrasting vector biology for transmission potential. Parasitology Todav 14:186-192.

- 2004. Tick ecology: processes and patterns behind the epidemiological risk posed by ixodid ticks as vectors. Parasitology 129: S37-S65.

Randolph, S. E., and A. D. M. Dobson. 2012. Pangloss revisited: a critique of the dilution effect and the biodiversity-buffers-disease paradigm. Parasitology 139:847-863.

2013. Commentary on "A Candide response to Panglossian accusations by Randolph and Dobson: biodiversity buffers disease" by Dr. R. Ostfeld (Parasitology 2013, in press). Parasitology 140:1199-1200.

Randolph, S. E., R. M. Green, A. N. Hoodless, and M. F. Peacey. 2002. An empirical quantitative framework for the seasonal population dynamics of the tick Ixodes ricinus. International Journal of Parasitology 32:979-989.

Reiter, P. 2001. Climate change and mosquito-borne disease. Environmental Health Perspectives 109:S141-S161.

Roche, B., P. Rohani, A. P. Dobson, and J.-F. Guégan. 2013. The impact of community organization on vector-borne pathogens. American Naturalist 181:1-11.

Rudolf, V. H. W., and J. Antonovics. 2005. Species coexistence and pathogens with frequency-dependent transmission. American Naturalist 166:112-118

Rueda, L. M., K. J. Patel, R. C. Axtell, and R. E. Stinner. 1990. Temperature-dependent development and survival rates of Culex quinquefasciatus and Aedes aegypti (Diptera: Culicidae). Journal of Medical Entomology 27:892-898.

Salkeld, D. J., K. A. Padgett, and J. H. Jones. 2013. A meta-analysis suggesting that the relationship between biodiversity and risk of zoonotic pathogen transmission is idiosyncratic. Ecology Letters 16:679-686.

Semenza, J. C., and B. Menne. 2009. Climate change and infectious diseases in Europe. Lancet Infectious Diseases 9:365-375.

Smallegange, R. C., G.-J. van Gemert, M. van de Vegte-Bolmer, S. Gezan, W. Takken, R. W. Sauerwein, and J. G. Logan. 2013. Malaria infected mosquitoes express enhanced attraction to human odor. PLoS ONE 8: e63602, http://dx.doi.org/10.1371/journal.pone.0063602.

Smith, D. L., F. E. McKenzie, R. W. Snow, and S. I. Hay. 2007. Revisiting the basic reproductive number for malaria and its im- 
plications for malaria control. PLoS Biology 5(3):e42, http://dx.doi .org/10.1371/journal.pbio.0050042.

Spielman, A., M. L. Wilson, J. F. Levine, and J. Piesman. 1985. Ecology of Ixodes dammini-borne human babesiosis and Lyme disease. Annual Review of Entomology 30:439-460, http://dx.doi.org/10.1146 /annurev.en.30.010185.002255

van Buskirk, J., and R. S. Ostfeld. 1995. Controlling Lyme disease by modifying the density and species composition of tick hosts. Ecological Applications 5:1133-1140.

Wesolowski, A., N. Eagle, A. J. Tatem, D. L. Smith, A. M. Noor, R. W. Snow, and C. O. Buckee. 2012. Quantifying the impact of human mobility on malaria. Science 338:267-270, http://dx.doi.org /10.1126/science.1223467.

Wonham, M. J., T. de-Camino-Beck, and M. A. Lewis. 2004. An epidemiological model for West Nile virus: invasion analysis and control applications. Proceedings of the Roval Societv B: Biological Sciences 271:501-507.
Wonham, M. J., M. A. Lewis, J. Rencławowicz, and P. van den Driessche. 2006. Transmission assumptions generate conflicting predictions in host-vector disease models: a case study in West Nile virus. Ecology Letters 9:706-725.

Wood, C. L., and K. D. Lafferty. 2013. Biodiversity and disease: a synthesis of ecological perspectives on Lyme disease transmission. Trends in Ecology and Evolution 28:239-247.

Wood, C. L., K. D. Lafferty, G. DeLeo, H. S. Young, P. J. Hudson, and A. M. Kuris. 2014. Does biodiversity protect humans against infectious disease? Ecology 95:817-832.

Young, H., R. H. Griffin, C. L. Wood, and C. L. Nunn. 2013. Does habitat disturbance increase infectious disease risk for primates? Ecology Letters 16:656-663.
Associate Editor: Pej Rohani

Editor: Judith L. Bronstein 